\title{
Bullough's bump: unusual protuberant fibro-osseous tumor of the temporal bone. Case report
}

\author{
Bowen Jiang, MD, ${ }^{1}$ Harry Mushlin, MD, ${ }^{2}$ Lei Zhang, MD, ${ }^{3}$ Aaron W. James, MD, PhD, ${ }^{3}$ and \\ Alan R. Cohen, MD'
}

\begin{abstract}
1Division of Pediatric Neurosurgery and ${ }^{3}$ Department of Pathology, Johns Hopkins School of Medicine; and ${ }^{2}$ Department of Neurosurgery, University of Maryland School of Medicine, Baltimore, Maryland
\end{abstract}

\begin{abstract}
Scalp and calvarial masses are common in children and the differential diagnosis is broad. The authors recently cared for a child with an unusual fibro-osseous lesion of the temporal bone that has previously not been described in the pediatric neurosurgery literature. A 10-year-old girl presented with a firm, slowly enlarging protuberant mass arising from the squamous suture of the temporal bone without intracranial extension. The mass was removed en bloc through a temporal craniectomy and cranioplasty was performed. The patient had a smooth postoperative course. Histological examination showed multiple oval osseous islands dispersed throughout a bland fibrous stroma. The pathological diagnosis was "Bullough's bump," a rare, benign fibro-osseous neoplasm first described in 1999, and only 8 reported cases appear in the literature. Here the authors report the first case of Bullough's bump in a child.
\end{abstract}

https://thejns.org/doi/abs/10.3171/2017.8.PEDS17391

KEY WORDS Bullough's lesion; Bullough's bump; protuberant fibro-osseous lesion; fibroosseous; craniofacial; skull neoplasm; exophytic

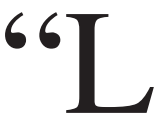

UMPS and bumps" on the head are common presentations in the pediatric neurosurgery population. The differential diagnosis is broad. Primary skull lesions in the form of benign or malignant neoplasms account for $1 \%-4 \%$ of bone tumors in children; in one institutional study, ${ }^{2}$ epidermoid/dermoid cyst and Langerhans cell histiocytosis were the most commonly encountered skull lesions. Although rare, Bullough's bump (protuberant fibro-osseous lesion of the skull) is an important clinicopathological entity that should be differentiated from other fibro-osseous lesions and other exophytic but nonfibrous lesions of the calvaria. We describe, to the best of our knowledge, the first pediatric case of Bullough's bump and examine the clinical, radiographic, and pathological findings of this unusual neoplasm. We also review the literature on this entity and offer suggestions for its neurosurgical management.

\section{Case Report}

History

An ambidextrous 10-year-old girl presented with a slowly enlarging, firm, visible and palpable, slightly tender left temporal skull-based mass. The mass was first noticed when patient was struck on the head with a toy truck when she was 3 years old. The mass enlarged slowly over the years. The child was born by cesarean section and had normal developmental milestones. There was a family history of polycystic kidney disease.

\section{Examination}

The occipital-frontal circumference was $53 \mathrm{~cm}$. There was a firm, raised left temporal skull-based mass measuring $4 \mathrm{~cm}$ in maximal diameter. The overlying scalp was slightly tender to the touch. Erythema was absent. The neurological examination was normal.

\section{Imaging}

A plain skull radiograph showed a wide-based bony exostosis. The superficial aspect of the mass had speculated margins and a somewhat sunburst appearance. Cranial CT scans without contrast medium showed a bulky, exophytic mass with a ground-glass matrix arising from the left temporal skull, causing elevation of the scalp over the left tem- 

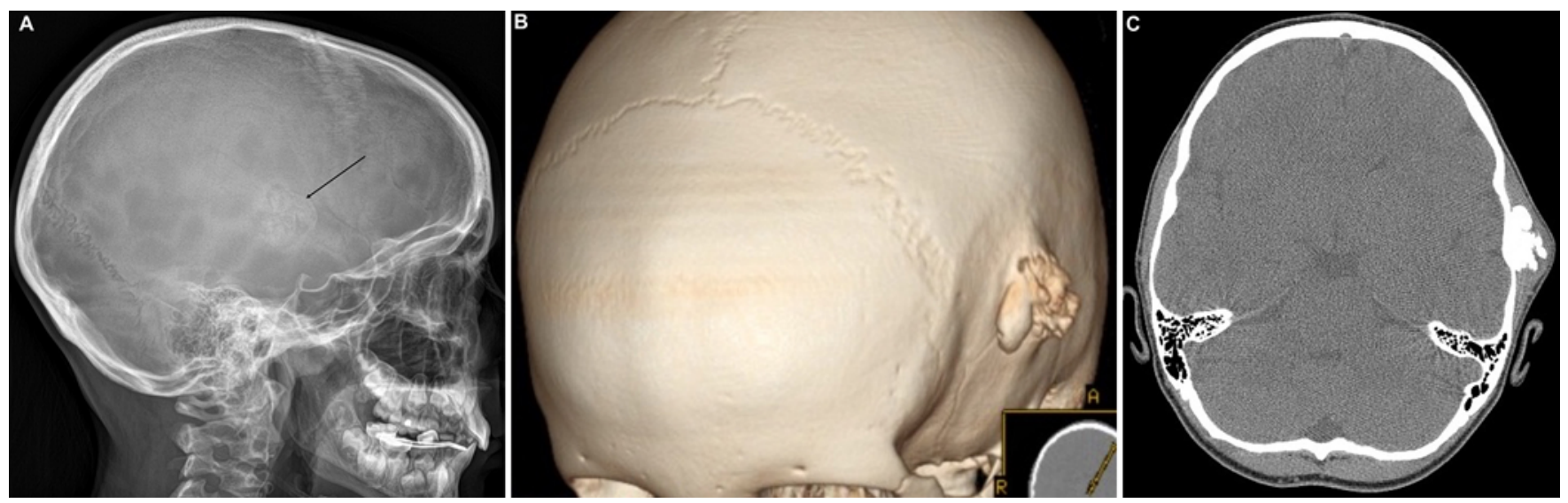

FIG. 1. Preoperative plain skull radiograph and cranial CT scans without contrast medium demonstrating Bullough's bump of the left temporal bone. A: Lateral plain skull radiograph showing a wide-based bony exostosis (arrow) arising from the left temporal calvaria and measuring $2.3 \times 4.1 \times 1.4 \mathrm{~cm}$. B: $3 \mathrm{D}$ rotation CT reconstruction of the lesion. C: Axial cranial CT scan, bone window, demonstrating a left temporal bone exophytic mass with a speculated and sunburst appearance. Figure is available in color online only.

poral bone. There was no dehiscence of the inner cortex of the skull and no evidence of intracranial extension (Fig. 1).

\section{Operation and Postoperative Course}

Surgery was carried out after induction of general endotracheal anesthesia. The mass was exposed using a linear incision through the scalp and temporalis muscle. The mass arose from the squamous part of the temporal bone at the squamosal suture and protruded superficially $3 \mathrm{~cm}$ above the plane of the skull. The mass was removed using 2 burr holes and a circumferential craniectomy fashioned using a high-speed drill and a footplate. The inferior margin of the bone compressed the dura slightly but did not penetrate it. A gross-total resection was performed and the defect was covered with an oval titanium mesh cranioplasty (Fig. 2). An autologous cranioplasty was considered but deferred due to the smallness of the cranial defect and the desire to avoid extension of the incision. The surgery was uncomplicated, and the patient had a smooth recovery. At the 6-month follow-up examination, the child was well, had no clinical evidence of recurrence, and also had no evidence of recurrence on a plain skull radiograph. We
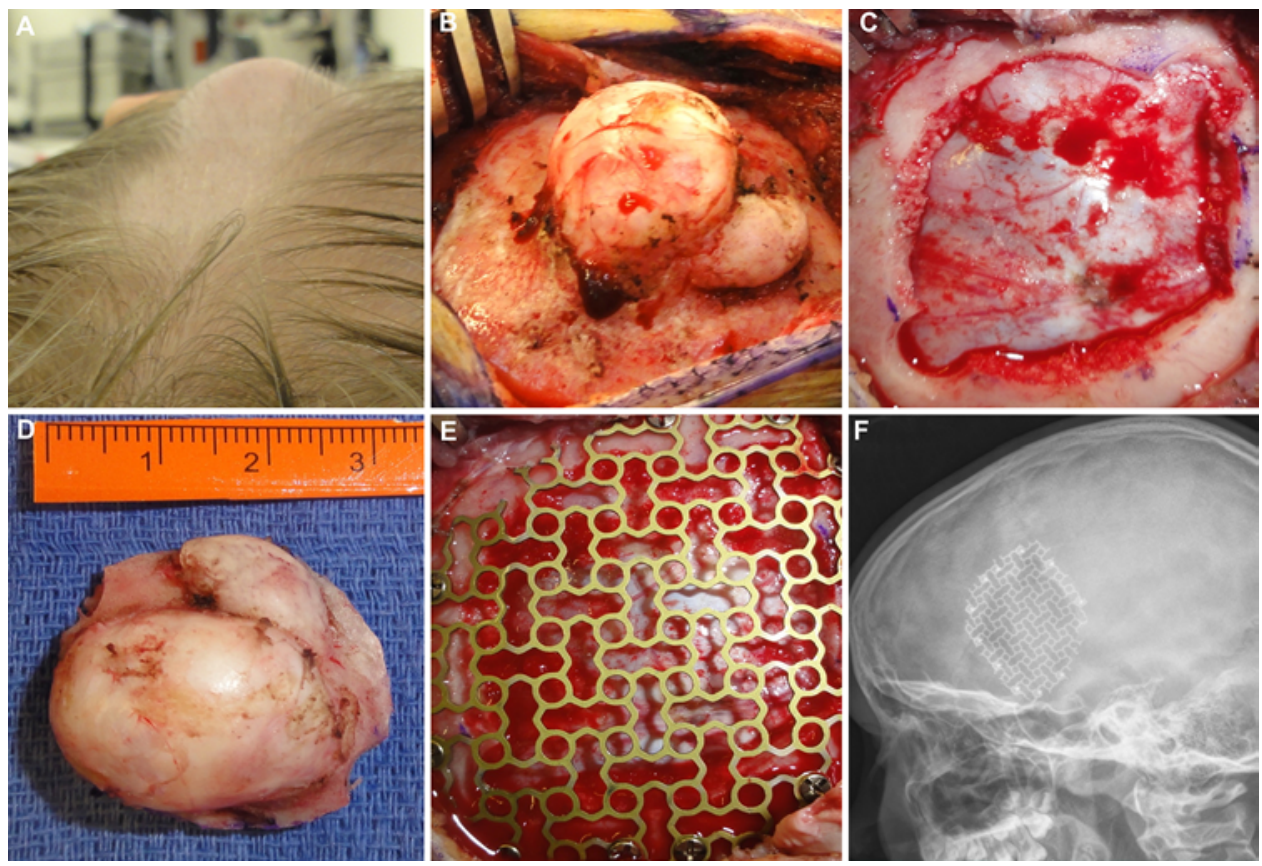

FIG. 2. A: Protuberant left temporal calvarial mass prior to incision. B: Scalp and temporalis muscle retracted to expose the exophytic tumor. C: Superior and inferior burr holes with craniectomy and en bloc excision. D: Resected mass. E: Titanium mesh cranioplasty for skull reconstruction. F: Lateral plain skull radiograph demonstrating resection of lesion. Figure is available in color online only. 


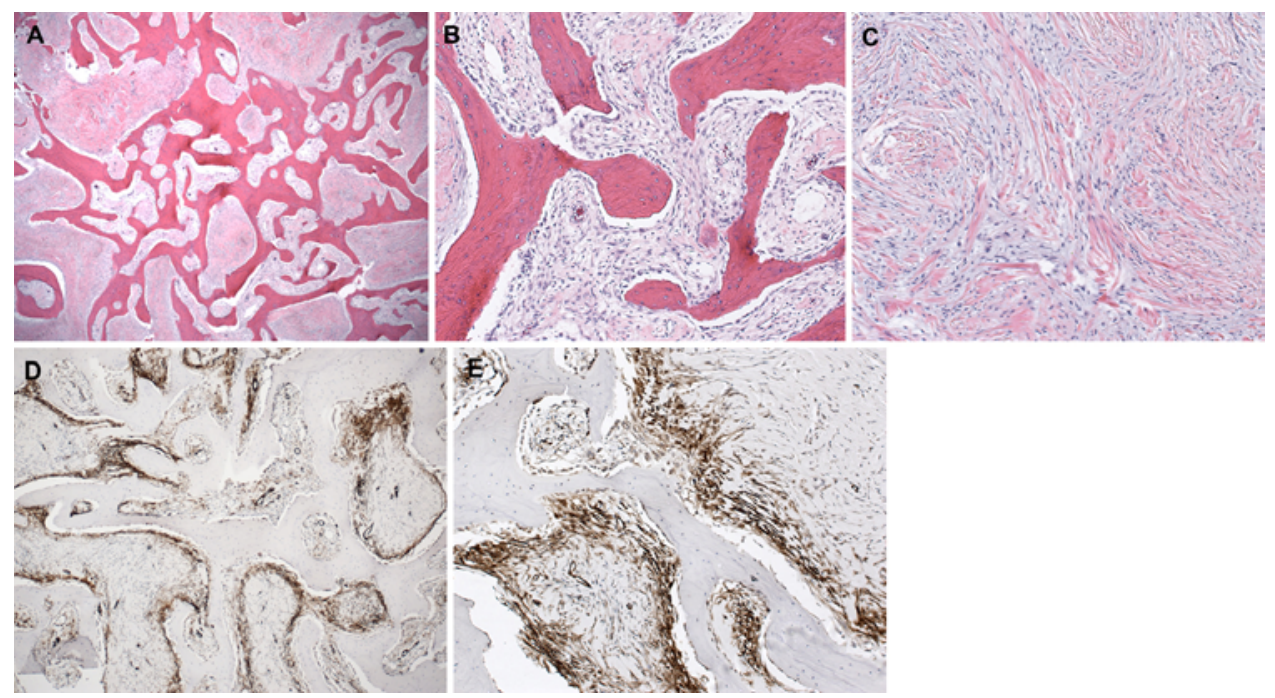

FIG. 3. Pathological and immunohistochemical examination of Bullough's bump. A: Low-magnification photomicrograph demonstrating a fibro-osseous tumor with mature and interconnected bony trabeculae arranged in a haphazard pattern. $\mathrm{H} \& \mathrm{E}$, original magnification $\times 2$. B: Higher-magnification photomicrograph demonstrating bone-lining osteoblasts in many microscopic fields. The fibrous stroma was composed of bland-appearing ovoid to spindled cells. Mitotic figures were inconspicuous. $\mathrm{H} \& \mathrm{E}$, original magnification $\times 10$. C: Photomicrograph demonstrating other areas of predominant fibrous tissue without bone and with more prominent collagen bundles. $\mathrm{H} \& \mathrm{E}$, original magnification $\times 10$. D and $\mathrm{E}$ : Immunohistochemical staining for smooth muscle actin highlighted spindle cells, particularly in a paratrabecular fashion. Magnifications $\times 4$ and $\times 10$, respectively. Figure is available in color online only.

plan to see the patient clinically on a yearly basis and conduct imaging only if clinically warranted.

\section{Pathological Findings}

The resection specimen measured $2.3 \times 4.1 \times 1.4 \mathrm{~cm}$ and was very firm. Histological examination showed a fibro-osseous tumor with mature and interconnected bony trabeculae arranged in a haphazard fashion (Fig. 3). Bonelining osteoblasts were seen along with bland-appearing ovoid and spindle-shaped cells in a fibrous stroma. Mitotic figures were inconspicuous. Other areas showed predominant fibrous tissue without bone, along with more prominent collagen bundles. Immunohistochemical staining for smooth muscle actin highlighted spindled cells, particularly in a paratrabecular fashion.

\section{Discussion}

We describe an unusual exophytic fibro-osseous lesion arising at the squamosal suture of the left temporal bone in a 10-year-old girl. The more common fibro-osseous lesions of the temporal bone include fibrous dysplasia and ossifying fibroma. Indeed, our initial clinical impression of this patient was that she had an osteoma or fibrous dysplasia. The exophytic variant of this fibro-osseous lesion (Bullough's bump) is rare, and the unique pathological findings are unique. Only 8 cases have been reported in the literature, with none appearing in the neurosurgical literature (Table 1).

The origin of the term, Bullough's bump, is an interesting story. Protuberant fibro-osseous lesions of the temporal bone were first described by Selesnick et al. in the American Journal of Otology in 1999.' They reported on 2 young adults, an 18-year-old man and a 21-year-oldwoman, who each presented with a nontender, palpable, and visually obvious posterior auricular mass without overlying soft-tissue erosion or abnormality. CT showed a heterogeneous ossified mass near the occipitomastoid suture. Both patients underwent excision of the mass and had a smooth postoperative course. Selesnick and colleagues defined the lesion as a benign tumor in which the normal bony architecture is replaced by a consortium of collagen, bland fibrous stroma, and calcified tissue. The exophytic nature of this fibro-osseous temporal bone lesion, along with its characteristic histopathology, is what makes it a unique clinical lesion.

In 2010 Sia et al. described the same clinicopathological entity in 2 adults, a 27 -year-old man and a 66-year-old woman, who each presented with a protuberant retroauricular mass without systemic involvement. ${ }^{8}$ During en bloc resection, the authors noted that the lesion was confined to the outer table of the calvaria, had well-circumscribed borders, and had no intraosseous involvement. They named the lesion for Peter G. Bullough, who described the pathology in the original 1999 report, and suggested that it be called Bullough's bump in his honor.

Dr. Bullough is a retired Professor of Anatomical Pathology at the Weill Cornell Medical Center, where he also served as Director of Laboratory Medicine at the Hospital for Special Surgery. According to Dr. Bullough, fibro-osseous lesions of the skull have been known for some time, but they are characteristically intramedullary in location. What is unique about Bullough's bump is the exophytic location and absence of intramedullary involvement. Through our communications with Dr. Bullough, we learned there were descriptions of this entity dating 
TABLE 1. Summary of cases of Bullough's bump

\begin{tabular}{|c|c|c|c|c|c|c|c|}
\hline Authors \& Year & No. of Cases & Age (yrs) & Sex & Lesion Location & Size (cm) & Management & Recurrence \\
\hline Current case & 1 & 10 & $\mathrm{~F}$ & Temporal & 4.1 & En bloc excision & No \\
\hline \multirow{2}{*}{ Sato et al., 2017} & 2 & 31 & $\mathrm{~F}$ & Occipital & 3.5 & En bloc excision & No \\
\hline & & 71 & $\mathrm{~F}$ & Occipital & 3.0 & En bloc excision & No \\
\hline \multirow{2}{*}{ Lee et al., 2014} & 2 & 54 & $\mathrm{~F}$ & Temporal & 5.5 & En bloc excision & No \\
\hline & & 70 & $\mathrm{~F}$ & Temporal & 2.9 & En bloc excision & No \\
\hline \multirow{2}{*}{ Sia et al., 2010} & 2 & 27 & M & Temporal & 2.0 & En bloc excision & No \\
\hline & & 66 & $\mathrm{~F}$ & Temporal & 3.2 & En bloc excision & No \\
\hline \multirow{2}{*}{ Selesnick et al., 1999} & 2 & 18 & $M$ & Temporal & 4.0 & En bloc excision & No \\
\hline & & 21 & $\mathrm{~F}$ & Temporal & 2.5 & En bloc excision & No \\
\hline
\end{tabular}

back to the 1970s, at which time it was perhaps classified within the broader realm of fibro-osseous lesions. It was only recently that the entity has been given a formal name and classified as a protuberant lesion distinct from other fibro-osseous tumors (P. B. Bullough, personal communication, 2017).

In 2014, Lee et al. described the same entity in 2 Korean women, ages 70 and 54 years. Both had painless posterior auricular masses that enlarged over several years. ${ }^{3}$ En bloc resection was carried out, and the authors found no evidence of intramedullary or intracranial extension. The lesions were tested for the R201H mutation in the GNAS gene, a mutation that has been implicated in the genetics of fibrous dysplasia. Interestingly, there was no R201H mutation in the either case, suggesting a different genetic pathophysiology for the Bullough's bump.

In 2017, Sato et al. described 2 cases of Bullough's bump in which the lesions arose from the occipital calvaria, as opposed to the previously reported lesions that arose from the temporal bone. ${ }^{6}$ Both patients were adult women who presented with slow-growing, painless palpable masses. Both patients underwent en bloc resection. The pathological findings were identical to those of the temporal bone cases, with the tumors exhibiting calcified or ossified oval islands surrounded by fibrocollagenous bland stroma. Growth of all reported lesions of Bullough's bump has behaved in an indolent manner.

All 4 series reported similar pathological findings of heterogeneous whitish-tan masses with extensive calcification that were confined to the surface of the outer table of the skull and exhibited no intramedullary or intracra- nial extension. Microscopically, multiple ovoid ossified islands of cells were seen intertwined by relatively acellular and bland fibrous stroma. The islands, although consisting of woven bone, did not contain mitotic activity, osteoblastic rims, or osteoclasts. These features distinguish the Bullough's bump from the other fibro-osseous lesions, such as fibrous dysplasia or ossifying fibroma (Table 2). It is worth noting that although only 8 cases of Bullough's bump have been reported in the literature, the true prevalence of this lesion could be significantly higher, as institutions unfamiliar with this lesion are likely to report it as a general fibro-osseous lesion and not identify it by its eponymous name or substratify according to its protuberant, exophytic, and extramedullary nature.

Clinically, fibrous dysplasia and ossifying fibromas of the temporal bone usually present in young adulthood (19-40 years of age) and have a slight male predominance. Hearing loss, otorrhea, and trismus are among the most common chief complaints. ${ }^{1}$ External auditory canal stenosis with canal cholesteatoma is a frequent finding. ${ }^{4}$ These nonprotuberant fibro-osseous lesions are usually rapidly growing and associated with systemic symptoms such as diffuse pain and headache. Finally, although fibro-osseous lesions are rare in the calvaria, they are not unusual in the craniofacial literature and are more commonly found in the mandible, maxilla, and nasal bones. ${ }^{5}$ It is important, therefore, to distinguish the exophytic Bullough's bump from fibrous dysplasia, as patients with Bullough's bump do not present with otological or generalized symptoms.

Furthermore, the differential diagnosis for bony tumors

TABLE 2. Comparison of Bullough's bump with fibrous dysplasia/ossifying fibroma

\begin{tabular}{llc}
\hline \multicolumn{1}{c}{ Category } & \multicolumn{1}{c}{ Bullough's Bump } & Fibrous Dysplasia/Ossifying Fibroma \\
\hline Demographics & Female predominance. Various ages. & Male predominance. Usually young adults. \\
\hline Clinical & $\begin{array}{c}\text { Protuberant, slow-growing, palpable, painless mass. } \\
\text { Usually arises from temporal or occipital bone. No } \\
\text { hearing loss or otorrhea. May have headache. }\end{array}$ & $\begin{array}{c}\text { Faster growing, less protuberant; can be painful. Usually arises from } \\
\text { craniofacial structures/jaw/mandible. May have hearing loss, otor- } \\
\text { rhea, trismus, \&/or headache. }\end{array}$ \\
\hline Radiology & $\begin{array}{c}\text { Calcified, heterogeneous, broad-based mass w/o } \\
\text { intramedullary or intracranial extension. }\end{array}$ & $\begin{array}{c}\text { Well-circumscribed lesion w/ intracortical osteolysis \& sclerotic band, } \\
\text { cortical expansion. May have endosteal scalloping. }\end{array}$ \\
\hline Pathology & $\begin{array}{c}\text { Bland, hypocellular, fibrocollagenous stroma w/ ossi- } \\
\text { fied, oval islands of various sizes. }\end{array}$ & $\begin{array}{c}\text { Dense lamellae w/ Haversian-like systems, bony trabeculae in various } \\
\text { shapes, osteoblastic rimming, \& trabecular/psammomas. }\end{array}$ \\
\hline
\end{tabular}


of the adult calvaria includes osteomas, osteoblastomas, giant cell tumors, osteosarcomas, metastatic lesions, eosinophilic granulomas, and myelomas. For children, the differential diagnosis is expanded to include epidermoid/ dermoid cysts, Langerhans cell histiocytosis, Ewing's sarcoma, and intraosseous hemangioma. ${ }^{2}$ Other exophytic masses found in the temporal bone include osteoma and osteoblastoma, which usually contain scant stroma or a nonfibrous stroma, respectively.

The pathogenesis of Bullough's bump is unclear. However, due to its predominant location in the temporal bone and its proximity to the occipitomastoid suture, the possibility of reactive inflammation with membranous bone formation secondary to trauma has been considered. ${ }^{8}$ In our patient, there was a remote history of minor trauma (the child was struck on the head with a toy truck at age 3 years), although it is unclear if this was the inciting factor or an incidental finding.

All previously reported cases of Bullough's bump have been in adults (mean age 40 years), and the majority of lesions (6 of 8 cases) have been found in women. In the majority (6 of 8) of cases, the lesions arose from the retroauricular temporal bone. Except for one case in which the lesion was $5.5 \mathrm{~cm}$ in diameter, the others were all less than $4 \mathrm{~cm}$ in diameter.

\section{Conclusions}

We describe the first case of Bullough's bump in a child. Like prior case descriptions, our patient was female and the lesion arose from the temporal bone. Unlike the other reported temporal lesions that arose from the occipitomastoid suture, ours was located more anteriorly, although it did overlie the squamosal suture. Our patient also had a benign postoperative course following en bloc resection, with no evidence of intramedullary or intracranial extension. Pathological features were identical to those described in prior reports, with bland stroma and calcified osseous islands.

Both clinically and pathologically, even for pathologists unfamiliar with Bullough's bump, the lesion's benign natural history portends an excellent long-term prognosis. As such, the recommended treatment is en bloc resection. Clinical follow-up is recommended but recurrence should be rare.

\section{References}

1. Couturier A, Aumaître O, Gilain L, Jean B, Mom T, André M: Craniofacial fibrous dysplasia: a 10-case series. Eur Ann Otorhinolaryngol Head Neck Dis 134:229-235, 2017

2. Gibson SE, Prayson RA: Primary skull lesions in the pediatric population: a 25-year experience. Arch Pathol Lab Med 131:761-766, 2007

3. Lee M, Song JS, Chun SM, Lee JH, Hong SH, Cho KJ: Protuberant fibro-osseous lesions of the temporal bone: two additional case reports. Am J Surg Pathol 38:1510-1515, 2014

4. Liu YH, Chang KP: Fibrous dysplasia of the temporal bone with external auditory canal stenosis and secondary cholesteatoma. J Int Adv Otol 12:125-128, 2016

5. Mainville GN, Turgeon DP, Kauzman A: Diagnosis and management of benign fibro-osseous lesions of the jaws: a current review for the dental clinician. Oral Dis 23:440-450, 2017

6. Sato N, Aoki T, Mukai N, Yotsumoto S, Irie K, Hisaoka M: Protuberant fibro-osseous lesion of the skull: two cases with occipital lesions. Virchows Arch 470:717-720, 2017

7. Selesnick SH, Desloge RB, Bullough PG: Protuberant fibroosseous lesions of the temporal bone: a unique clinicopathologic diagnosis. Am J Otol 20:394-396, 1999

8. Sia SF, Davidson AS, Soper JR, Gerarchi P, Bonar SF: Protuberant fibro-osseous lesion of the temporal bone: "Bullough lesion". Am J Surg Pathol 34:1217-1223, 2010 (Erratum in Am J Surg Pathol 34:1888, 2010)

\section{Disclosures}

The authors report no conflict of interest concerning the materials or methods used in this study or the findings specified in this paper.

\section{Author Contributions}

Conception and design: Cohen, Jiang. Acquisition of data: Jiang, Zhang, James. Analysis and interpretation of data: Jiang, Mushlin. Drafting the article: Jiang, Mushlin, Zhang. Critically revising the article: Cohen, Jiang, Mushlin. Reviewed submitted version of manuscript: Cohen, Jiang. Approved the final version of the manuscript on behalf of all authors: Cohen. Administrative/technical/material support: Cohen, James. Study supervision: Cohen, James.

\section{Correspondence}

Alan R. Cohen, Department of Neurosurgery, Division of Pediatric Neurosurgery, Johns Hopkins University School of Medicine, 600 North Wolfe St., Phipps 556, Baltimore, MD 21287. email: alan.cohen@jhmi.edu. 